\title{
Effects of carbon blacks with various structures on vulcanization and reinforcement of filled ethylene-propylene-diene rubber
}

\author{
Z. H. Li, J. Zhang*, S. J. Chen \\ College of Materials Science and Engineering, Nanjing University of Technology, Nanjing 210009, P. R. China
}

Received 10 June 2008; accepted in revised form 27 August 2008

\begin{abstract}
The effects of carbon blacks on vulcanization and mechanical properties of filled ethylene-propylene-diene rubber (EPDM) are investigated, by comparing with five types of rubber-grade carbon blacks. Curing kinetics is studied by rheometer and the results indicate that the curing characteristics are influenced by combination of surface area of carbon black and sulphur content on the filler surface, because the former one enhances the physical cross-linking and the latter one introduces the additional chemical cross-linking. Both the degree of cross-linking and cure rate increase with increasing surface area and sulphur content, whereas the optimum cure time and scorch time decrease. The reinforcing nature of the carbon black is assessed from mechanical measurements. It is suggested that the surface area of carbon blacks strongly affects the physical properties of EPDM/carbon black composites. Conductive carbon black (N472) can be used as desirable reinforcing filler due to the higher degree of cross-linking of EPDM with N472 than other EPDM/carbon black composites. The morphology and distribution of particles are studied by using scanning electron microscope. The sound reinforcing ability of N472 is also supported by scanning electron microscope due to the notable dispersibility of N472 within EPDM matrix. N472 ensures the EPDM/N472 composite the most conductive sample among the five composites.
\end{abstract}

Keywords: polymer composites, ethylene-propylene-diene rubber, carbon black, cure kinetics, mechanical properties

\section{Introduction}

Elastomers are presently used in wide areas of application, such as wires, cables and automobiles, due to their light weight, hydrophobicity, easy maintenance and processing. Nevertheless, they have been usually applied in the filled state since Mote and others discovered the reinforcement of rubber by carbon black a century ago [1]. Reinforcing fillers include carbon blacks, silica and resins, which increase the strength of vulcanized rubber more than tenfold [2, 3]. Filling carbon blacks in elastomers and plastics also reduces the cost of the end product and modifies the electrical and optical properties of the polymer matrix $[4,5]$.
Reinforcement of rubber by carbon blacks has been intensively studied [6-9]. It is generally accepted that the reinforcement of elastomers and the improvement of other properties, to a large extent, are associated with the chemical and physical interactions between the polymer matrix and carbon blacks [10-14]. Thus, researchers try to explain the improved performance of rubber from the microscopic view, relating the observation of cure kinetics and mechanical properties with the interactions between elastomers and carbon blacks $[15,16]$. The entanglement of rubber molecules on the carbon black surface is supposed to play an important role for rubber attachment on carbon blacks [9]. The aggregate anisometry is associated with the

*Corresponding author, e-mail: zhangjun@ njut.edu.cn

(C) BME-PT and GTE 
Table 1. Surface and structure parameters for the carbon blacks under study

\begin{tabular}{|c|c|c|c|r|r|r|}
\hline Samples & SCB & N770 & N550 & N330 & N472 \\
\hline Surface parameters & \multicolumn{5}{|l|}{} \\
\hline$S_{B E T}\left[\mathrm{~m}^{2} / \mathrm{g}\right]$ & 8.20 & 15.80 & 37.80 & 81.10 & 1039.50 \\
\hline$S_{e x}\left[\mathrm{~m}^{2} / \mathrm{g}\right]$ & 4.87 & 13.55 & 33.38 & 68.36 & 981.62 \\
\hline Carbon & 92.80 & 88.50 & 92.74 & 89.85 & 90.52 \\
\hline Oxyements on the surface (at.\%) & 6.76 & 11.50 & 6.97 & 9.35 & 8.50 \\
\hline Sulphur & 0.44 & $*$ & 0.29 & 0.70 & 0.97 \\
\hline
\end{tabular}

Note: $S_{B E T}$ - standard BET specific surface areas; $S_{e x}$ - external surface area; *not detected

DBP absorption capacity, which is proportional to the entangled rubber chains [6]. Also, the adsorption of ethylene-propylene-diene rubber (EPDM) upon the surface of carbon blacks was studied by Litvinov and coworkers via nuclear magnetic resonance (NMR) [8]. They found the rubber molecule physically adsorbed on the carbon black surface and the reinforcement increases as the EPDM-carbon black interfacial area enhances. Park and coworkers did a lot of work about the relationship between the surface energy of carbon blacks and the resulting mechanical properties of carbon black/rubber composites [16-18]. They concluded that an increase of nonpolar characteristics (London dispersive component of the surface energy of carbon blacks), which is affected by the specific surface area, results in increasing vulcanization reactions and improvements of the mechanical properties of the composites [17]. Besides the specific area, the surface chemistry of carbon black has a significant effect on the properties of carbon black filled elastomers. It is reported that the mechanical properties of composites correspondingly changed with the modification of carbon blacks dispersed in the rubbers. Léopoldès's group found that higher $100 \%$ and $300 \%$ moduli were observed for the natural rubber filled with a modified carbon black, which was treated by oxidative gas [19]. Scanning electron microscope (SEM) is a technique used to probe the filled rubber $[20,21]$. The carbon black mainly exists as the primary aggregation in rubber [2, 22].

The priority of preparing favorable rubber is to obtain the tailor-made cure and mechanical properties. Thus, in this work we compare the cure kinetic characteristics and mechanical properties of EPDM filled with conductive carbon black and other rubber-grade carbon blacks, in order to arrive at a comprehensive understanding of the influences of the structure of the carbon black on the EPDM/carbon black composites.

\section{Experimental}

\subsection{Materials}

The samples of EPDM (J-4045) are supplied by Jilin Chemical Industrial Company limited, China. The content of ethylidene norbornene (ENB), the third monomer of EPDM, is $8.0 \mathrm{wt} \%$. According to the standard ASTM D1765-06, the carbon black used in this work includes high abrasion furnace (N330), and fast extruding furnace black (N550) (both N330 and N550 are from Suzhou Carbon Black Plant, China), semi-reinforcing furnace black (N770, Luzhou Carbon Black Plant, China), spraying carbon black (SCB, Fushun Carbon Black Company Ltd., China) and conductive carbon black (N472, HG-1B, Huaguang Chemical Company, China). The main structural parameters of carbon blacks are listed in Table 1.

\subsection{Compounding of EPDM}

The compounding formulations (in weight per hundred weight of rubber (phr)) used in this work are listed in Table 2. The mixing or compounding of EPDM with dicumyl peroxide (DCP) and other additives was carried out in a two roll mixer (Shanghai rubber machinery works, China) at $30 \sim 40^{\circ} \mathrm{C}$, following the conventional technique [23]. An overall mixing time of $15 \mathrm{~min}$ was

Table 2. Formulation of mixes

\begin{tabular}{|l|c|}
\hline \multicolumn{1}{|c|}{ Ingredients } & Loading [phr] \\
\hline EPDM gum stock & 100 \\
\hline Zinc oxide & 5 \\
\hline Stearic acid & 1 \\
\hline DCP & 4 \\
\hline Antioxidant 4010NA & 1 \\
\hline Carbon Black & 30 \\
\hline
\end{tabular}


allowed in each case to ensure uniform and efficient dispersion of the carbon black filler particles in the elastomer matrix.

\subsection{Vulcanization of EPDM}

The vulcanization characteristics of the EPDM/carbon black composites were determined in an oscillating disk cure meter (Wuxi Liyuan Electronically Chemical Equipment Co. Ltd., China), based on ASTM D 2084-01, at $160^{\circ} \mathrm{C}$. The optimum cure time was obtained from torque-time curves given by the rheometer. The compounded elastomers described earlier were prepared into vulcanizates in a platen vulcanizing press under a pressure of $10 \mathrm{MPa}$ and at a temperature of $160^{\circ} \mathrm{C}$ for $20 \mathrm{~min}-$ utes.

\subsection{Hardness and tensile test}

The hardness of the carbon black filled EPDM vulcanizates was measured by a Shore A durometer following the ASTM D 2240-03 standard. Dogbone shaped specimens $(\sim 25 \mathrm{~mm}$ long in the middles by $\sim 6 \mathrm{~mm}$ wide by $\sim 2 \mathrm{~mm}$ thick) for tensile test were cut from plates. Tensile tests $(25 \mathrm{~mm}$ initial jaw separation, $500 \mathrm{~mm} / \mathrm{min}$ displacement speed) were performed on a universal mechanical testing machine (China) according to standard ASTM D412-98a.

\subsection{SEM}

The EPDM/carbon black composite samples were fractured in liquid nitrogen. Then, the cross sections of samples were sputtered with $\mathrm{Au}$ in vacuum. The morphology of the cross section of carbon black filled EPDM at the magnification of 5000x and $20000 \times$ was studied by SEM using a JEOL

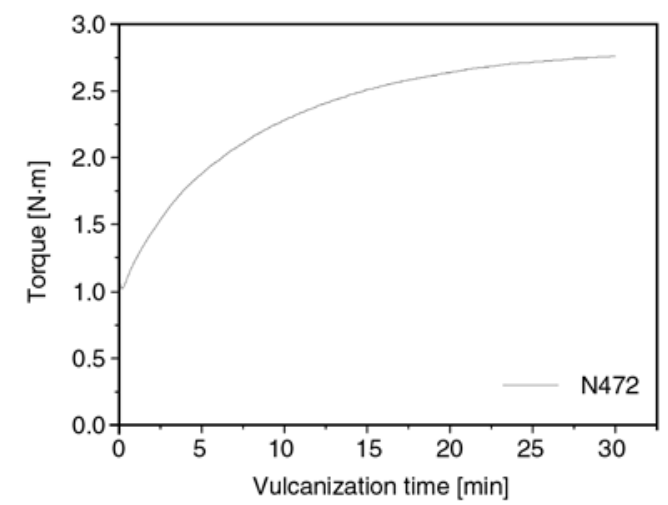

JSM-5900 instrument (Japan) with an accelerating voltage of $15 \mathrm{kV}$.

\subsection{Volume resistivity measurements}

The volume resistivity of composites with a high resistivity was measured by a high resistance meter (Shanghai Precision \& Scientific Instrument Co., Ltd, China). The resistivity of EPDM filled with N472 was measured by a conventional four-point probe technique in which the electrodes were separated by $1 \mathrm{~mm}$ as reported [24]. The four probes were slightly pressed on the EPDM samples to ensure a good contact. The electrical property measurements were all performed at room temperature. The volume resistivity measured by the four point method is calculated as Equation (1):

$R_{v}=\frac{R b h}{l}$

where $R_{v}$ is the volume resistivity [ $\left.\Omega \cdot \mathrm{m}\right], R$ is the electrical resistance $[\Omega], b$ and $h$ are the width and height of the sample, respectively (the section area is the value that $b$ multiple by $h$ ), and $l$ is the distance between the two probes (1 $\mathrm{mm}$ in this work).

\section{Results and discussion}

\subsection{Cure kinetics}

The rheometer, a convenient instrument to evaluate the effects of carbon black-rubber interactions on rate of cure and cross-linking, was employed for the purpose of characterizing critical parameters related to the vulcanization process. Figure 1 shows the separate vulcanization curves of EPDM/carbon black composites at $160^{\circ} \mathrm{C}$, associated with the various natures of carbon blacks. As illustrated in

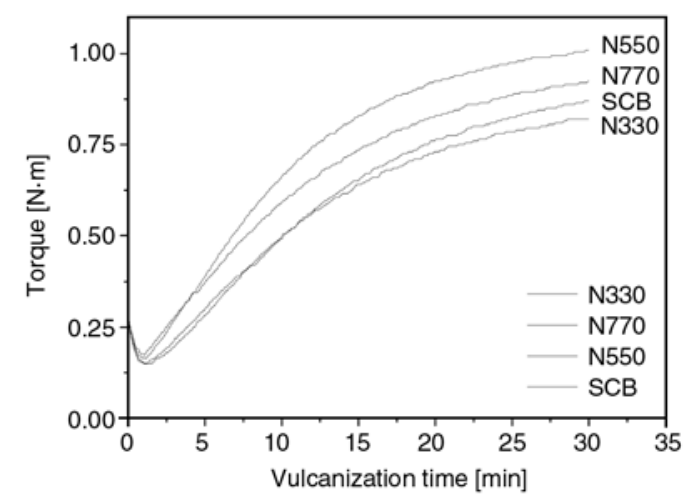

Figure 1. Rheocurves of the EPDM/carbon black composites at $160^{\circ} \mathrm{C}$ filled with: (a) conductive carbon black; (b) other 4 types of carbon blacks 
Table 3, the minimum torque, $M_{L}(1.03 \mathrm{~N} \cdot \mathrm{m})$, the maximum torque, $M_{H}(2.76 \mathrm{~N} \cdot \mathrm{m})$, and the difference between them, $\Delta M=\left(M_{H}-M_{L}\right)(1.73 \mathrm{~N} \cdot \mathrm{m})$, of N472 are much higher than those of other carbon blacks. This is not surprising if physical and chemical interactions of EPDM and carbon black are fully studied.

While the uncured EPDM is being blended well with carbon black for a period of time, EPDM chains have a certain probability to contact with carbon black, and entangle or trap in the voids of carbon black aggregates. As displayed in Figure 2, the rubber chains become highly immobilized and localized, and form a rubber shell, with an estimated thickness of $0.7 \mathrm{~nm}$, surrounding the carbon black particles [9]. Figure 3 demonstrated that those carbon black particles whose surfaces were covered by entangled EPDM chains can be considered as physical cross-links [8]. The physical crosslinking hinders the mobility of rubber chains and restrains the deformation of rubber; thus the $M_{L}$ of filled EPDM enhances even it is at the uncured state.
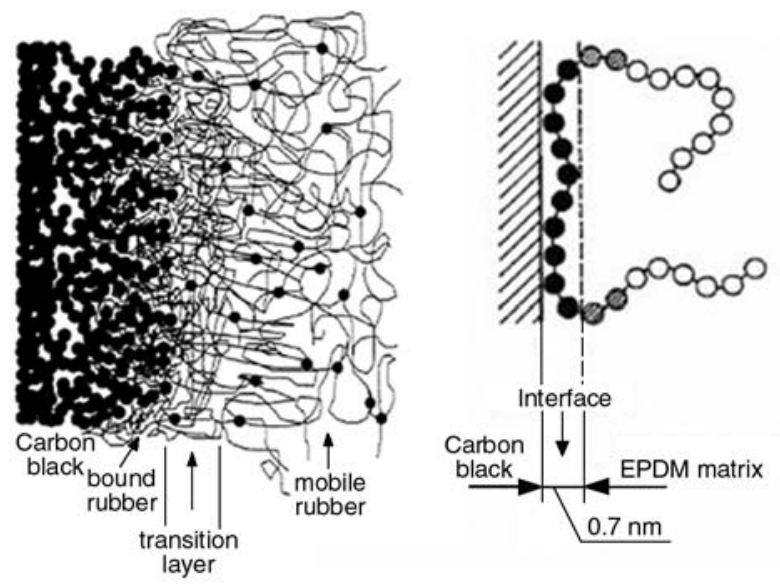

Figure 2. Sketch of the entanglement of rubber chains with carbon black: (a) The entanglement of EPDM chains on carbon black; (b) The thickness of the interface between carbon black and EPDM matrix [8, 9]

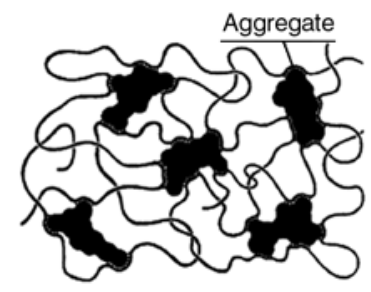

Figure 3. Scheme of the physical network structure in a carbon black filled elastomers [8]

Hence, it is understandable that development of a large polymer-filler interface is the most important factor for the degree of reinforcement provided by filler. Therefore, the surface area of carbon black is of great importance for the density of the physical cross-linking. As the surface area of carbon black increases, the number of rubber chains entangling with carbon black aggregates as well as that of the cross-links climbs up [8]. The entanglement of polymer chains with carbon black increases the torque; thereby the carbon black serves as physical cross-links in rubbers. $M_{L}$, the torque of melting uncured rubbers at $160^{\circ} \mathrm{C}$, is an indicator of the degree of physical cross-linking.

Most properties, such as Mooney viscosity and $300 \%$ modulus, of filled rubber depend on the specific surface area of carbon black, and $M_{L}$ is the one of them [6]. $M_{L}$ increases correspondingly with the increasing surface area of carbon black, as the number of rubber chains immobilized on the carbon black surfaces grows up. It can be seen in Table 1 that both the BET specific surface area $\left(1039.50 \mathrm{~m}^{2} / \mathrm{g}\right)$ and external surface area $\left(981.62 \mathrm{~m}^{2} / \mathrm{g}\right)$ of $\mathrm{N} 472$ are remarkably higher than those of other carbon blacks, even over 100 times larger than the lowest value. Moreover, not only N472 but also other 4 types of carbon blacks confirm the surface area of particle has a great impact on the $M_{L}$. The $M_{L}$ of all 5 types of carbon blacks exhibit the strikingly similar order with that of carbon black surface area. The physical EPDM-filler interaction explains that the surface area of carbon

Table 3. Vulcanization properties of the carbon black/EPDM composites

\begin{tabular}{|l|r|r|r|r|r|}
\hline & SCB & N770 & N550 & N330 & N472 \\
\hline$M_{L}[\mathrm{~N} \cdot \mathrm{m}]$ & 0.15 & 0.15 & 0.16 & 0.17 & 1.03 \\
\hline$M_{H}[\mathrm{~N} \cdot \mathrm{m}]$ & 0.87 & 0.82 & 1.01 & 0.93 & 2.76 \\
\hline$\Delta M[\mathrm{~N} \cdot \mathrm{m}]$ & 0.72 & 0.67 & 0.85 & 0.76 & 1.73 \\
\hline$T_{S 1}[\mathrm{~min}]$ & 4.23 & 3.80 & 2.93 & 2.97 & 0.52 \\
\hline$T_{90}[\mathrm{~min}]$ & 22.40 & 21.95 & 20.40 & 21.67 & 17.77 \\
\hline$V_{C 1}$ & 5.50 & 5.51 & 5.72 & 5.35 & 5.80 \\
\hline
\end{tabular}

Note: $M_{H}$ - the maximum torque; $M_{L}$ - the minimum torque; $\Delta M=M_{H}-M_{L} ; T_{S 1}$ is equal to the time for $0.1 \mathrm{~N} \cdot \mathrm{m}$ that rise above $M_{L}$;

$T_{90}$ - optimum cure time, the time for the torque that is equal to the $90 \%$ of $\Delta M ; V_{C 1}$ is Cure Rate Index 
black plays a major role for influencing the $M_{L}$ of EPDM/carbon black composite.

$M_{L}$ is cure property measured in the uncured state; nevertheless, $\Delta M$ is the characteristic of the cured rubbers. During the vulcanization process, the chemical cross-linking forms based on the reaction of rubbers with vulcanization reagent [25]. $\Delta M$, the difference between $M_{H}$ and $M_{L}$, is thereby considered as the parameter to demonstrate the degree of chemical cross-linking. The $\Delta M$ of all EPDM filled with five types of carbon blacks are supposed to be comparable, because the same type of vulcanization reagent (DCP in this work) is equally loaded. The fact, however, is that $M_{H}$ and $\Delta M$ of the filled EPDM vary with the type of the carbon black.

Hence, it is evident that the reaction of rubbers with vulcanization reagent is merely one factor influencing the cross-linking process. The other one is the chemical bonding of rubbers with the functional groups on carbon blacks $[2,6,7]$. The chemical bonding of rubbers with carbon blacks increases the degree of chemical cross-linking. Sulphur on the surface of carbon blacks most probably improved the vulcanization. It is noted in Table 1 that sulphur is observed on the surfaces of four types of carbon blacks. It is accepted that sulphur vulcanization takes place at an appropriate temperature as long as the recipe includes a sulphur donor, zinc oxide, fatty acid [26]. Therefore, according to the report, sulphur cross-links form during vulcanization since the carbon blacks with sulphur on the surface can be considered as the sulphur donors and the ingredients of the recipe mentioned can be found in formulation of EPDM composites. Further investigation shows that the $\Delta M$ is in the same order as the amount of sulphur (elemental composition multiple with external surface area of carbon black) when N330 is excluded. The $\Delta M$ of EPDM filled with $\mathrm{N} 770$ is merely $0.67 \mathrm{~N} \cdot \mathrm{m}$, less than other composites, due to the absence of sulphur on the surface of N770. Thus, EPDM filled with N770 is the only rubber which vulcanizes without the influence of sulphur on the surface of carbon black. On the other hand, N472 has not only the largest external surface area but also higher value of surface sulphur content than other carbon blacks; therefore, EPDM filled with N472 inevitably has larger $\Delta M$ than those filled with other blacks. N330 is the exception because the phenolic group, which is reported to reduce the cross-linking efficiency, is only found on N330 surface; as a result, the value of $\Delta M(0.76)$ of N330 is lower than N550 (0.85).

As displayed in Table 3, $T_{s 1}, T_{90}$ and $V_{C 1}$ are the parameters associated with the vulcanization rate. In this study, despite the peroxide vulcanization, the sulphur on the surface of carbon blacks, as XPS results show, possibly plays an important role in the cross-linking process. The incorporation of sulphur into peroxide vulcanization dramatically reduces the cure time, because sulphur also can react with the ENB in EPDM to form cross-linking [26]. Nevertheless, the content of sulphur is highly associated with the surface area of carbon black. N472 has the largest surface area amongst the carbon blacks under study, and thereby the content of sulphur on N472 is higher than other carbon blacks. This explains that EPDM filled with N472 has the shortest scorch time $\left(T_{s 1}=0.52 \mathrm{~min}\right)$ and optimum cure time $\left(T_{90}=17.77 \mathrm{~min}\right)$.

According to ASTM standard mentioned earlier, Cure Rate Index $\left(V_{C 1}\right)$ is a measurement of vulcanization rate based on the difference between optimum vulcanization and incipient scorch time, at which vulcanization begins. $V_{C 1}=100 /$ (cure time scorch time). Therefore, the shortest optimum cure time of EPDM with N472 inevitably results in the highest value of $V_{C 1}$ (5.80) among the EPDM/carbon black composites under study. The highest $V_{C 1}$ of EPDM with N472 indicates the fastest cure rate in all those 5 types of EPDM/carbon black composites. It is interesting to note that N330 has the lowest cure rate owing to the quinolic group, which slows down the speed of cross-linking process, observed on the surface of N330 [27-29].

The conversion ratio, $\chi_{t}$, at a given time $t$ is defined as Equation (2) based on the rheocurves, as shown in Figure 4, to compare the rate of vulcanization in details [17].

$\chi_{t}=\frac{M_{t}-M_{L}}{M_{H}-M_{L}}$

where $M_{t}$ represents the torque at a given time $t, M_{H}$ and $M_{L}$ are the maximum and minimum torques, respectively.

Figure 4 displays the conversion of EPDM/carbon black composites for carbon blacks with different external surface areas as a function of cure time. The rate of conversion of vulcanization reaction under a given condition is observed in the order 


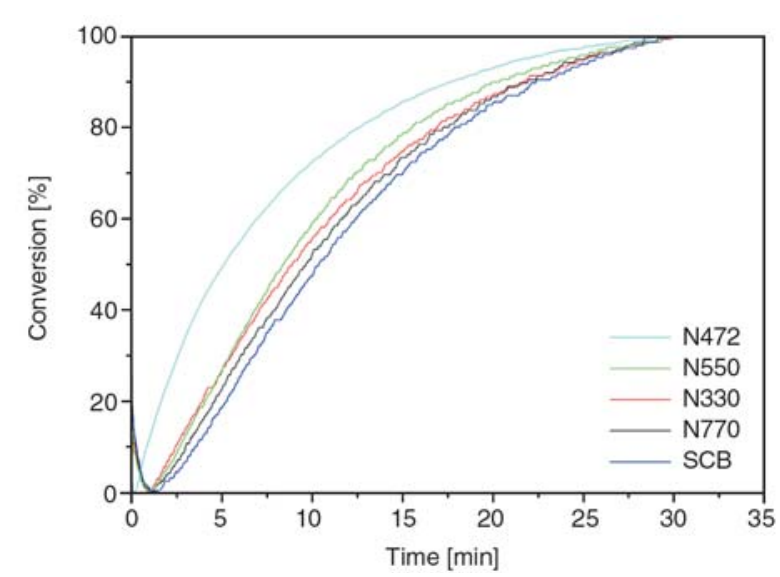

Figure 4. Conversion ratio of the carbon black/EPDM composites

N472 $>$ N550 > N330 > N770 > SCB. For instance, the $50 \%$ conversion demands about $5.13 \mathrm{~min}$ for $\mathrm{N} 472,8.41 \mathrm{~min}$ for $\mathrm{N} 550,8.88 \mathrm{~min}$ for N330, $9.63 \mathrm{~min}$ for $\mathrm{N} 770$, and $10.35 \mathrm{~min}$ for SCB. The reactivity in vulcanization reaction is raised with increasing surface functional groups of carbon blacks, while the reaction is inhibited by increasing acidity, supported by the appearance of quinolic structure, in the rubber composites [10, 27-29].

Almost all cure characteristics vary proportionately with external surface area, due to more opportunities for formation of the increasing chemical and physical interactions on larger surface. There are also some exceptions. It should be noted that for N330, although with strikingly larger external surface area than N550, the degree of cross-linking and vulcanization rate are lower than those of N550. This is due to the cure retarding effect of quinine and carboxylic acid functionalities attached on the surface of N330 determined in FT-IR [10]. Carbon blacks inhibit free radical reactions through quinonic surface groups; these reactions also result in formation of polymer grafts [2].

\subsection{Mechanical properties and reinforcement}

During tests of mechanical properties, remarkable modifications of rubbers which are termed as 'rein- forcement', both physical and chemical interactions involved. Table 4 indicates five parameters of mechanical properties of EPDM/carbon black composites used to reflect the different reinforcing abilities among those composites.

Hardness, which is one of the most obvious mechanical parameters, varies in a considerable range from 52 to 79 Shore A. The former one corresponds to SCB, while the latter one matches with N472, the carbon black with largest external surface area. The degree of cross-linking has a great effect on the hardness of the elastomer [2]. The highest surface sulphur content of N472 possibly contributes to the hardness of EPDM filled with N472. The higher degree of chemical cross-linking induced by peroxide and sulphur vulcanization and physical crosslinking by entanglement ensure the EPDM vulcanizate the larger ability to resist deformation. Also, it is reported that the rubber chains are entangled with or permanently locked in carbon black aggregates and form a rigid shell. The amount of shell increases with the increasing surface area of carbon black; thus, the largest area of rigid rubber shell is obtained on the N472 surface since it has the largest external surface area, which is accessible for rubber molecules. The rigid shell causes the enhancement of hardness of total EPDM composite. Thus, EPDM filled with N472 is the example that larger particle surface area induces harder composite (79 Shore A).

Plotting the hardness against the surface area, it can be seen from Figure 5 that the hardness jumps up with the external surface area. In addition, the correlation factor $\left(R^{2}\right)$ for the linear regression in this diagram is strikingly high $\left(R^{2}=0.92\right.$, hardness vs. external surface area of carbon black). This suggests that the external surface area of carbon blacks is indeed a major factor determining the hardness of EPDM/carbon black composites. In fact, this generally agrees with the reports in the literature [6]. According to Litvinov's report, it is not surprising that the surface area of a carbon black contributes markedly to the hardness, because of the external

Table 4. Mechanical properties of EPDM/carbon black composites

\begin{tabular}{|c|c|c|c|c|c|}
\hline & SCB & N770 & N550 & N330 & $\mathbf{N} 472$ \\
\hline Hardness [Shore A] & 57 & 52 & 60 & 59 & 79 \\
\hline $300 \%$ modulus [MPa] & 4.67 & 2.91 & 5.17 & 5.23 & 15.12 \\
\hline Tensile strength [MPa] & 8.44 & 12.12 & 15.04 & 18.38 & 17.76 \\
\hline Elongation at break [\%] & 510 & 640 & 526 & 571 & 345 \\
\hline Permanent set [\%] & 12 & 17 & 15 & 15 & 17 \\
\hline
\end{tabular}




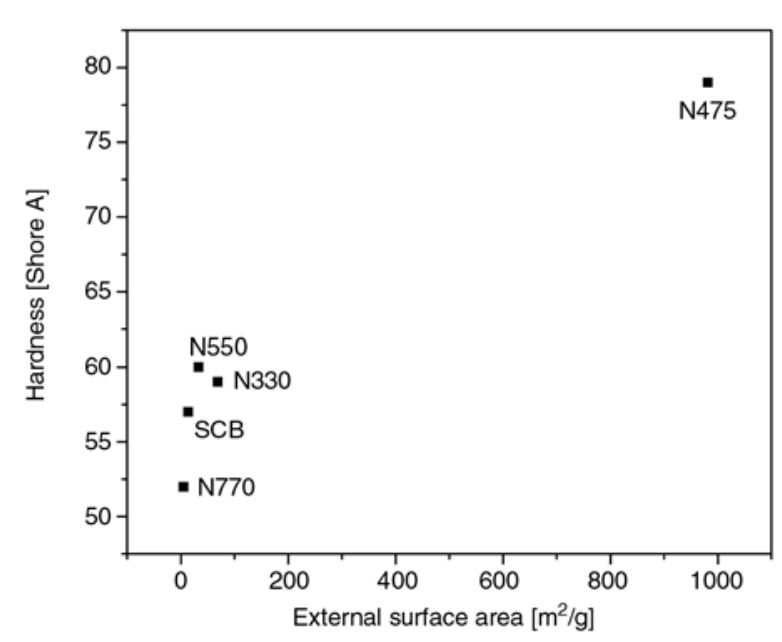

Figure 5. Hardness as a function of the external surface area of carbon blacks

surface which is accessible to polymer chains and provides a place for them to immobilize [8]. And it is reported that the amount of bound rubber increases with the increasing irregularity of filler surface [30]. This is probably due to that, when the filler loading is the same, the larger surface has more irregularity and hence more bound rubber. Thus, it actually can be expected that larger surface area inevitably rises dramatically the possibility of immobilization of rubber molecules on surface of blacks. Therefore, the whole composite transforms from soft to stiff, owing to the loss of segmental mobility of polymer chains and consequently decreased flexibility of the rubber matrix. Similarly, it is reported that high-structure, that is high external surface area, carbon blacks tend to shorten the elongation at break due to its higher strain amplification degree. Therefore, elongation at break of composites, as Table 4 demonstrated, dropped from $640 \%$ (N770) to $345 \%$ (N472), inversely proportional to the external surface area, and their correlation factor $\left(R^{2}=0.79\right)$ is reasonably high, indicating the significant effect of surface area [6].

$300 \%$ modulus, a parameter widely used to characterize the stiffness of rubber vulcanizates, is the stress at $300 \%$ extension. The structure of carbon black is one factor to influence the $300 \%$ modulus by strain amplification and occluded rubber. In addition, the cross-linking density is another parameter to affect the $300 \%$ modulus [2]. As mentioned earlier, the $\triangle M$ of EPDM filled with N472 is 1.73 , much larger than other composites, suggesting the higher value of density of cross-linking.
Hence, it is reasonable that $300 \%$ modulus of EPDM filled N472 (15.12 MPa) ranks as the first in all composites. What is more, the correlation factor $R_{2}$ of tensile modulus at $300 \%$ vs. external surface area is 0.97 , also indicating the notable influence of surface area. It is noted that tensile strength of filled EPDM passes through a maximum peak then reduces, as the $\Delta M$, the typical parameter representative cross-linking density, of composite increases. N472 with the shockingly huge surface area has lower tensile strength at break $(17.76 \mathrm{MPa})$ than that of N330 (18.38 MPa). This confirms the literature that the tensile strength experiences the bell curve with increasing density of cross-linking. Thus, it is no surprise that the correlation factor $R^{2}$ of tensile strength at break vs. external surface area is only 0.26 , but it climbs up to 0.92 when the $\mathrm{N} 472$ is excluded.

As far as the elongation at break of filled EPDM is concerned, when plotting it vs. external surface area $R^{2}$ is reduced to 0.77 . In order to fully understand the influencing factors for elongation of break, it is necessary to thoroughly investigate the breaking process of dumb bell composite samples. During the uniaxial tensile test, the sample was stretched to a large strain, and when the stress exceeds the stress-relieving capacity of the occluded rubber, it begins to rupture [6]. Mechanisms include stress relief and de-wetting. The difference between those two processes is that the former one is detachment of chains in a given area, whereas the latter one is the slippage of weakly bonded chains during large deformation [2]. The number of weak bonds, which are formed by physical adsorption to anchor polymer chains on filler surfaces, is affected by the surface area. Thus, according to above correlation factors $R^{2}$, the surface area is one the most important, probably the most important factor which affects mechanical properties. Another factor is the elemental concentration probed by XPS. As the XPS spectra shown, the highest amount of sulphur exists on N472 surface but is not detected on the surface of N770. The cross-linking density, thus, varies with the surface sulphur content. The increasing degree of cross-linking is responsible for the improved mechanical properties of filled rubber, because the action of large number of rubber chains was locked or cross-linked by entanglement and vulcanization. Therefore, the largest degree of 
cross-linking EPDM filled with N472 leads to the lowest elongation at break (345\%) in all composite, acting more like a plastic.

Permanent set is the parameter often applied in the rubber industry to characterize the resilience of the rubber. SCB-containing sample has the lowest permanent set $(12 \%)$ whereas those of samples filled with $\mathrm{N} 472$ and N770 are in the middle position (both are 15\%). Samples with N770 and N472 have the highest permanent set (17\%).

\subsection{SEM}

SEM is commonly applied method to observe the morphology of rubber/carbon black composites $[22,31,32]$. The morphologies of the carbon black filled EPDM are shown in Figure 6. The carbon black mainly exits as the aggregates in the rubber matrix [2]. Almost all types of carbon black aggregates distribute uniformly in EPDM. Nevertheless, the size of the carbon black aggregates varies with the type of the carbon black. The carbon black aggregates for N472 and N330 have the smaller sizes than other aggregates. In the SEM of EPDM/ N472 and EPDM/N330 composites, the carbon black can be hardly distinguished. Generally, the filler with large surface has a small size. As Table 1 demonstrated, N472 and N330 have the higher BET specific surface areas $\left(1039.50\right.$ and $81.10 \mathrm{~m}^{2} / \mathrm{g}$, respectively) than others. Therefore, N472 and
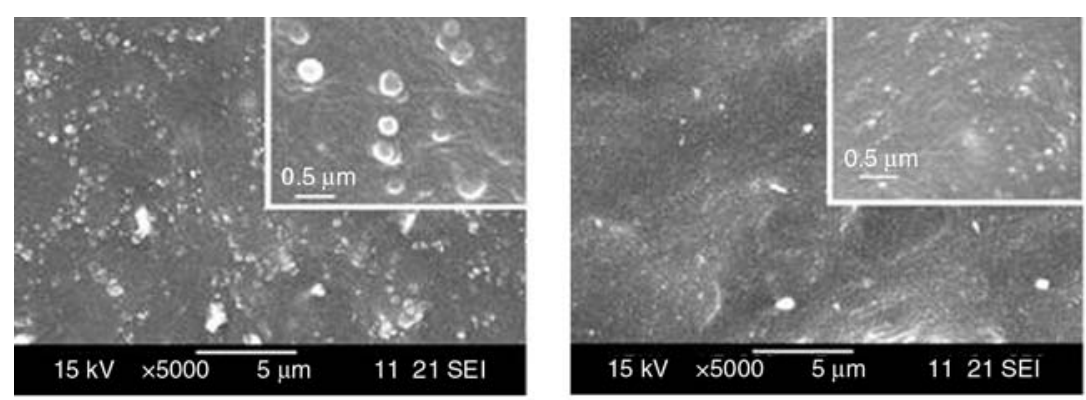

b)

a)

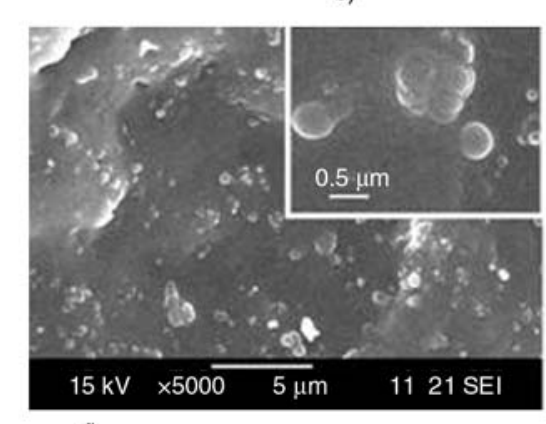

d)
N330 have the lower values of the aggregate sizes. The unclear interface between N472 and EPDM indicates the miscibility of N472 with EPDM, which brings to the filled EPDM sound mechanical properties. In addition, in our other research, carbon blacks with small size induce the high value of conductivity into rubber. In the SEM of N770, SCB and N550, the interfaces between carbon black aggregates and the EPDM matrix are evident. Hence, the reinforcing ability of N770, SCB and N550 are less significant than N472. Although N550 has the larger size than N770 in SEM, N550 have higher value of BET specific surface. This is ascribed to the porosity of N550. The rubber molecules are able to access into the particle of N550 but not to that of N770. Thus, N550 has the better reinforcing performance than N770.

\subsection{Electrical resistivity}

Electrons usually transport easily on the carbon black surfaces. Hence, the addition of carbon blacks not only reinforces the composites but also introduces electrical conductivity into filled rubber. Electrical conduction of filled EPDM has been extensively researched for a period of long time $[23,33]$. There are mainly three mechanisms, including conduction path theory, electron tunneling theory and electric field radiation theory, of the

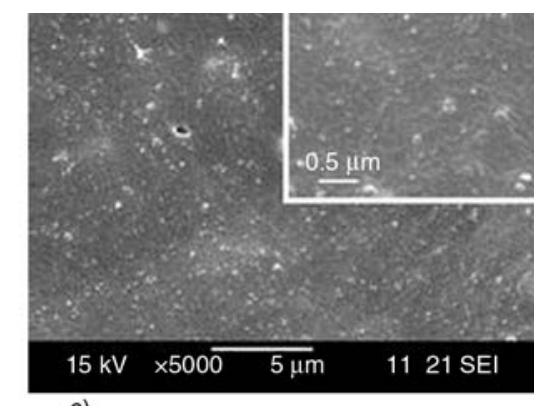

c)

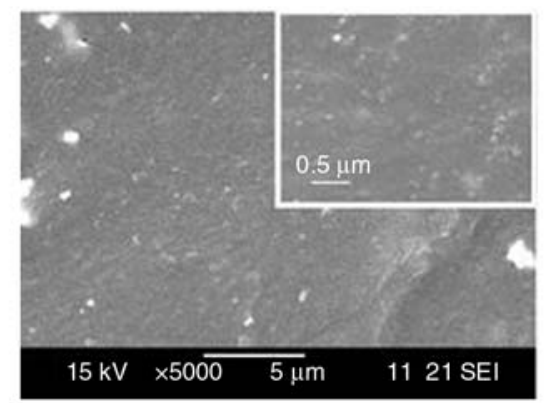

e)

Figure 6. The SEM of EPDM/carbon black composites with different carbon blacks: (a) N770; (b) N330; (c) SCB; (d) N550; (e) N472 
Table 5. Volume resistivity of EPDM/carbon black composites

\begin{tabular}{|c|c|c|c|c|}
\hline $\mathbf{N 7 7 0}^{\mathbf{a}}$ & $\mathbf{S C B}^{\mathbf{a}}$ & $\mathbf{N 5 5 0}^{\mathbf{a}}$ & $\mathbf{N 3 3 0}^{\mathbf{a}}$ & $\mathbf{N 4 7 2}^{\mathbf{b}}$ \\
\hline $2.3 \times 10^{14} \Omega \cdot \mathrm{m}$ & $2.0 \times 10^{14} \Omega \cdot \mathrm{m}$ & $1.8 \times 10^{11} \Omega \cdot \mathrm{m}$ & $1.2 \times 10^{10} \Omega \cdot \mathrm{m}$ & $0.18 \Omega \cdot \mathrm{m}$ \\
\hline
\end{tabular}

Note: $\mathrm{a}-$ the sample was characterized by the high resistance meter;

$\mathrm{b}$ - the sample was characterized by the conventional four-point technique

electrical conduction in the polymer filled with carbon blacks [30].

The significant factor influencing the electrical conduction mechanisms is the percolation limit. The percolation limit is the loading where the conduction paths start to form. The percolation limit of carbon blacks varies with the surface area. The carbon black with large surface area has low percolation limit. It is noted in Table 5 that the volume resistivity $(0.18 \Omega \cdot \mathrm{m})$ of EPDM filled with $\mathrm{N} 472$ is considerably lower than other EPDM/carbon black composites. The low resistivity indicates that EPDM with N472 is suitable to be used in conductive applications. The content of N472 (30 phr) effortlessly exceeds the percolation limit. Thereby, the carbon black aggregates of N472 form a few continuous networks by contacting with each other. Consequently, those networks act as the conductive paths in EPDM/N472 composites; thus the volume resistivity is smaller than the lower limit of high resistance meter [34]. The volume resistivity of EPDM filled with N550 and N330 are $1.8 \cdot 10^{11}$ and $1.2 \cdot 10^{10} \Omega \cdot \mathrm{m}$, respectively. And SCB and N770 have the lower surface areas than other carbon blacks, hence the volume resistivity of EPDM filled with the two carbon blacks are $2.0 \cdot 10^{14}$ and $2.3 \cdot 10^{14} \Omega \cdot \mathrm{m}$, separately. Accordingly, the EPDM filled with those four types of rubber-grade carbon blacks are the insulators. Their loadings of carbon black are lower than the percolation limit. Therefore, the electron transmission in those carbon black is mainly electron tunneling theory and electric field radiation theory [34]. Additionally, it is reported that the heteroatoms such as oxygen and sulphur on the surface of carbon blacks have effects on the resistivity because some functional groups including $\mathrm{OH}$ group traps electrons which transport on the filler surface [30].

\section{Conclusions}

In this research, the cure kinetics of EPDM filled with conductive carbon black and other rubber grade black were investigated. The vulcanization and mechanical properties of the cured EPDM/carbon black composites were measured. The experimental results show surface area of carbon black as well the sulphur content on the surface of carbon black has influences on the cure kinetics of EPDM/ carbon black composites. As the surface area of carbon blacks increases, the physical cross-linking is enhanced. In addition, the sulphur on the surface of carbon black also plays an important role in the vulcanization of EPDM/carbon black composites, since it introduce the additional chemical crosslinking into the system. Mechanical experimental results demonstrate that the composite with conductive carbon black, comparing with other blacks, has the highest hardness, tensile strength at break, tensile modulus at $300 \%$ and permanent set. This is due to the high degree of cross-linking of the EPDM filled with N472. The elongation at break of this composite with conductive carbon black is lower than those with other blacks due to the EPDM molecule firmly absorbed on the N472 surface. The SEM results also indicate the sound reinforcing ability of N472 owing to the notable miscibility of N472 with EPDM matrix. The EPDM/ N472 composite has the significantly higher volume resistivity than other samples.

\section{References}

[1] Blow C. M., Hepburn C.: Rubber technology and manufacture. Butterworth Scientific, London (1982).

[2] Eirich F. R.: Science and technology of rubber. Academic Press, New York (1978).

[3] Khan M. S., Lehmann D., Heinrich G.: Modification of PTFE nanopowder by controlled electron beam irradiation: A useful approach for the development of PTFE coupled EPDM compounds. Express Polymer Letters, 2, 284-293 (2008).

[4] Pantea D., Darmstadt H., Kaliaguine S., Roy C.: Electrical conductivity of conductive carbon blacks: Influence of surface chemistry and topology. Applied Surface Science, 217, 181-193 (2003).

[5] Pantea D., Darmstadt H., Kaliaguine S., Roy C.: Heattreatment of carbon blacks obtained by pyrolysis of used tires. Effect on the surface chemistry, porosity and electrical conductivity. Journal of Analytical and Applied Pyrolysis, 67, 55-76 (2003). 
[6] Donnet J., Vidal A.: Carbon black: Surface properties and interactions with elastomers. in 'Advances in Polymer Science' (eds.: Abe A., Albertsson A-C., Duncan R., Dusek K., de Jeu W. H., Kausch H-H., Kobayashi S., Lee K-S., Leibler L., Long T. E., Manners I., Möller M., Nuyken O., Terentjev E. M., Voit B., Wegner G., Wiesner U.) Springer Berlin, Heidelberg, 103-127 (1986).

[7] Edwards D. C.: Polymer-filler interactions in rubber reinforcement. Journal of Materials Science, 25, 4175-4185 (1990).

[8] Litvinov V. M., Steeman P. A. M.: EPDM-carbon black interactions and the reinforcement mechanisms, as studied by low-resolution ${ }^{1} \mathrm{H}$ NMR. Macromolecules, 32, 8476-8490 (1999).

[9] Heinrich G., Vilgis T. A.: Contribution of entanglements to the mechanical properties of carbon blackfilled polymer networks. Macromolecules, 26, 11091119 (1993).

[10] Barlow F. W.: Rubber compounding: Principles, materials, and techniques. Marcel Dekker, New York, (1988).

[11] Wolff S., Wang M. J.: Filler-elastomer interactions. Part III: Carbon-black-surface energies and interactions with elastomer analogs. Rubber Chemistry and Technology, 64, 714-735 (1991).

[12] Wolff S., Wang M. J.: Filler-elastomer interactions. Part IV: The effect of the surface energies of fillers on elastomer reinforcement. Rubber Chemistry and Technology, 65, 329-342 (1992).

[13] Wolff S.: Chemical aspects of rubber reinforcement by fillers. Rubber Chemistry and Technology, 69, 325-346 (1996).

[14] Fröhlich J., Niedermeier W., Luginsland H. D.: The effect of filler-filler and filler-elastomer interaction on rubber reinforcement. Composites Part A: Applied Science and Manufacturing, 36, 449-460 (2005).

[15] Leblanc J. L.: Rubber-filler interactions and rheological properties in filled compounds. Progress in Polymer Science, 27, 627-687 (2002).

[16] Park S-J., Kim J-S.: Role of chemically modified carbon black surfaces in enhancing interfacial adhesion between carbon black and rubber in a composite system. Journal of Colloid and Interface Science, 232, 311-316 (2000).

[17] Park S-J., Seo M-K., Nah C.: Influence of surface characteristics of carbon blacks on cure and mechanical behaviors of rubber matrix compoundings. Journal of Colloid and Interface Science, 291, 229-235 (2005).

[18] Park S-J., Cho K-S., Ryu S-K.: Filler-elastomer interactions: Influence of oxygen plasma treatment on surface and mechanical properties of carbon black/rubber composites. Carbon, 41, 1437-1442 (2003).

[19] Léopoldes J., Barres C., Leblanc J. L., Georget P.: Influence of filler-rubber interactions on the viscoelastic properties of carbon-black-filled rubber compounds. Journal of Applied Polymer Science, 91, 577588 (2004)
[20] Wang J. H., Liang G. Z., Yan H. X., He S. B.: Mechanical and dielectric properties of epoxy/dicyclopentadiene bisphenol cyanate ester/glass fabric composites. Express Polymer Letters, 2, 118-125 (2008).

[21] Das A., Jurk R., Stöckelhuber K. W., Heinrich G.: Rubber curing chemistry governing the orientation of layered silicate. Express Polymer Letters, 1, 717-723 (2007).

[22] Zhang A., Wang L., Lin Y., Mi X.: Carbon black filled powdered natural rubber: Preparation, particle size distribution, mechanical properties, and structures. Journal of Applied Polymer Science, 101, 1763-1774 (2006).

[23] Ghosh P., Chakrabarti A.: Conducting carbon black filled EPDM vulcanizates: Assessment of dependence of physical and mechanical properties and conducting character on variation of filler loading. European Polymer Journal, 36, 1043-1054 (2000).

[24] Chen S., Chen W., Si Z., Zhou D., Xue G.: Preparation of size controllable polypyrrole sub-Microcapsules using SEBS copolymer as the building block. Macromolecular Rapid Communications, 27, 328-332 (2006).

[25] Habeeb Rahiman K., Unnikrishman G., Sujith A., Radhakrishnan C. K.: Cure characteristics and mechanical properties of styrene-butadiene rubber/acrylonitrile butadiene rubber. Materials Letters, 59, 633-639 (2005).

[26] Akiba M., Hashim A. S.: Vulcanization and crosslinking in elastomers. Progress in Polymer Science, 22, 475-521 (1997).

[27] Zaper A. M., Koenig J. L.: Solid state carbon- ${ }^{13}$ NMR studies on vulcanized elastomers. III: Accelerated sulfur vulcanization of natural rubber. Rubber Chemistry and Technology, 60, 278-297 (1987).

[28] Morita E.: Correlation analysis of curing agents. Rubber Chemistry and Technology, 57, 744-754 (1984).

[29] Cotten G.: The effect of carbon black surface properties and structure on rheometer cure behavior. Rubber Chemistry and Technology, 45, 129-144 (1972).

[30] Medalia A. I.: Electrical conduction in carbon black composites. Rubber Chemistry and Technology, 59, 432-454 (1986).

[31] Guriya K. C., Tripathy D. K.: Morphology and physical properties of closed-cell microcellular ethylene-propylene-diene terpolymer (EPDM) rubber vulcanizates: Effect of blowing agent and carbon black loading. Journal of Applied Polymer Science, 62, 117-127 (1996).

[32] Akovali G., Ulkem I.: Some performance characteristics of plasma surface modified carbon black in the (SBR) matrix. Polymer, 40, 7417-7422 (1999).

[33] Sau K. P., Chaki T. K., Khastgir D.: The change in conductivity of a rubber-carbon black composite subjected to different modes of pre-strain. Composites Part A: Applied Science and Manufacturing, 29, 363 370 (1998).

[34] Sau K. P., Chaki T. K., Khastgir D.: Conductive rubber composites from different blends of ethylenepropylene-diene rubber and nitrile rubber. Journal of Materials Science, 32, 5717-5724 (1997). 